\title{
ORAL HEALTH RELATED QUALITY OF LIFE BY MEANS OF FUNCTIONAL CHANGES IN GERIATRIC ORAL HEALTH ASSESSMENT INDEX (GOHAI) BEFORE AND AFTER INSERTION OF NEW CONVENTIONAL COMPLETE DENTURES IN COMPLETELY EDENTULOUS PATIENTS.
}

\footnotetext{
1. BDS, FCPS

Assistant Professor

Department of Prosthodontics College of Dentistry King Khalid University,

Abha Kingdom of Saudi Arabia.

2. BDS, FCPS

Associate Professor

Department of Prosthodontics

Lahore Medical \& Dental College, Lahore.

3. BDS, FCPS

Assistant Professor

Department of Prosthodontics

College of Dentistry King Khalid University

Abha Kingdom of Saudi Arabia.

4. BDS, FCPS

Assistant Professor

Department of Prosthodontics

Bibi Asifa Dental College, Larkana.

5. BDS, FCPS

Assistant Professor

Department of Periodontology

College of Dentistry, Zia-u-Din University, Karachi.

6. BDS

Lecturer

Department of Oral Maxillofacial

Surgery

Bibi Aseefa Dental College, Larkana.
}

\section{Correspondence Address:}

Dr. Shabir Ahmad

Department of Prosthodontics

Bibi Asifa Dental College, Larkana.

Near Oil Depot Muhalla Rahmat Pur

Larkana Sindh.

ahmedshabir80@gmail.com

Article received on:

14/01/2019

Accepted for publication:

19/04/2019

\section{INTRODUCTION}

Dentofacial problems have several effects on patients' satisfaction by means of their dentition as they influence aesthetics, performance and functions. ${ }^{1}$ Tooth loss involve the usual functional activities ensuing in a variety of reactions in edentulous patients. The dentition is one of the mainly significant elements in any judgement regarding a person's appearance..$^{2,3}$ Loss of teeth can be a troubling emotional incident for several people which may be psychologically depressing. ${ }^{4}$
Gotam Das ${ }^{1}$, Khezran Qamar' ${ }^{2}$ Muhammad Haseeb Rana ${ }^{3}$, Shabir Ahmed ${ }^{4}$, Zaheer Hussain Chachar ${ }^{5}$, Kinza Mushtaque ${ }^{6}$ health disrupts the regular life and common functioning of an individual. To evaluate the oral health problems of older adults, Geriatric Oral Health Assessment Index (GOHAl) can be used. GOHAl was developed by Atchinson and Dolan ${ }^{3}$ before and after complete denture therapy". Study Design: Cross sectional study. Setting: Department of Prosthodontics, Lahore Medical and Dental College, Lahore. Period: February 18, 2018 to August 17, 2018. Material \& Methods: Patients will be selected for the study according to the criteria. Patient history and clinical examination was undertaken. Upper and lower complete dentures was made-up for 30 patients (both male and female) using standardized clinical and laboratory methods. Conventional procedures were applied to complete denture construction. Complete dentures were constructed in the similar dental laboratory within the institution by compression moulding method. Laboratory and clinical remount procedures, beside with occlusal corrections were carried out using a semi-adjustable articulator. The GOHAl questionnaire was completed on two different appointments. First questionnaire was documented before denture insertion and second questionnaire was recorded after complete denture insertion. Results: Before treatment mean GOHAl score was $20.46 \pm 2.85$ and after treatment mean GOHAl score was improved and was $26.32 \pm 2.34$. The mean GOHAl score was statistically improved p-value $<0.001$. For male patients, before treatment mean GOHAl score was $21.61 \pm 2.59$ and after treatment mean GOHAl score was improved and was 26.31 \pm 2.14 . The mean GOHAl score was statistically improved in male patient, $p$-value $<0.001$. For female, before treatment mean GOHAl score was $19.34 \pm 2.70$ and after treatment mean GOHAl score was improved and was $26.44 \pm 2.49$. The mean GOHAl score was statistically improved in female patients, p-value < 0.001 . Conclusion: According to patient's information enhancement in functional changes after placement of complete dentures.

Key words: $\quad$ Geriatric Oral Health Assessment Index (GOHAI), Oral Health Impact Profile (OHIP), Quality of Life (QOL). complete dentures in completely edentulous patients. Professional Med J 2019; 26(12):2085-2089. DOI: 10.29309/TPMJ/2019.26.12.3128 
patients is conventional complete dentures. It is widely accepted being relatively cheap, aesthetically satisfactory and easy to clean. ${ }^{2}$ The prognosis of conventional complete dentures is unpredictable depending upon the patient's adaptive capacity. ${ }^{6}$ Removable prosthesis still at their best but have various functional limitations on patients. The provision of new complete dentures should be assessed by patient's point of vision. ${ }^{7}$

The quality of life can be judged by assessing individual's subjective feelings of pleasure or dissatisfaction regarding different life concerns. ${ }^{7}$ The oral health associated quality of life (OHRQoL) procedures to which oral health disrupts the normal life and social functioning of a person. ${ }^{8}$ Difficulties of phonetic, esthetic, mastication or disability as a consequence of tooth loss creates harmful impact on quality of life. ${ }^{9}$ Prosthodontic treatment should have the practical and psychological adaptation by the patient to progress in better quality of life. ${ }^{10}$ Before after therapy patient based evaluation tool aid the clinicians to improve the quality of life. ${ }^{11}$

Complete dentures are the most frequent form of prosthetic treatment for edentulism. In Pakistan, complete edentulism occurs an estimated $4.1 \%$ of the population aged 65 years and over, with a predictable increase to $9.3 \%$ by $2030 .{ }^{12}$ QHRQoL has been considered to evaluate the impact of edentulism and available therapies measured by OHIP. ${ }^{13}$ Comparing OHRQoL of elder adults wearing complete and partial dentures established that removable partial denture patients experience more impaired OHRQoL than complete dentures wearers. ${ }^{14}$

A number of OHRQoL tools have been used to evaluate the prosthodontic therapies. These OHRQoL gadgets have been revealed to work very well in relating the impact of edentulism and treatment on numerous domains. ${ }^{14}$ The Geriatric Oral Health Assessment Index (GOHAI) is an instance of patients based measurement of oral health problems generally affecting older adults. ${ }^{15}$ Objective of this study was to evaluate the changes in GOHAI before and after placement of conventional complete dentures in edentulous patients.

\section{MATERIALS AND METHODS}

Permission was taken from the hospital ethical committee and informed consent was taken from the patients. Patients of $60-84$ age group are included in this study. The patient must be completely edentulous. Patients having no history of denture wearing i.e. new complete denture wearers. Patients fulfilling the inclusion criteria were chosen from the department of Prosthodontics, Lahore Medical and Dental College, Lahore. Patient history and clinical examination were undertaken then patients selected for the study according to the criteria. Maxillary and Mandibular complete dentures fabricated for 30 patients (both male and female) through standardized clinical and laboratory procedures. Conventional procedures were employed to complete denture construction. All the complete dentures were processed in the same dental laboratory within the institution by compression moulding method. Laboratory and clinical remount procedures, along with occlusal corrections were completed using a semiadjustable articulator. The GOHAI questionnaire was completed on two different phases. One questionnaire will be recorded prior denture insertion. One questionnaire will be recorded after complete denture insertion.

While the items were scored on a 5-point scale, the GOHAl was administered using a three-point scale (always, sometimes, never). GOHAI scale scores at baseline and 1 month were calculated as a simple summation of the 11 items (response set is always, very often, often $=1$, sometimes, seldom $=2$, never $=3$ ) after reversing the response set of three items (item 3: swallow comfortably; item 5: eat anything without feeling discomfort; item 7: happy with looks). A simple summative score ranging from 11 to 33 will be calculated for every patient, with a higher score indicating better self-reported oral health. Means, median values, standard deviations and change scores will calculate for the GOHAl. Change in GOHAl score will be calculated as the followup score minus the score at baseline. ${ }^{7}$ The data 
will be analyzed by using Wilcoxon signed-rank test. All the data analysis will be carried out using SPSS version 21 . A probability value, $p$ value of less than 0.05 will be considered statistically significant.

\section{RESULTS}

In current study the mean age of subjects was $71.78 \pm 7.60$ with minimum and maximum age of 60 years and 84 years. Table-I

There were 24(43.6\%) patients who were 60-70 years of age, $20(35.71 \%)$ were $71-80$ years old and $11(19.64 \%)$ patients were $>80$ years age. Table-II

The average age of man patients was $68.5 \pm 6.54$ years and average age of women patients was 75 \pm 7.25 years. Table-III

Before treatment mean GOHAI score was 20.46 \pm 2.85 and after treatment mean GOHAl score was improved and was $26.32 \pm 2.34$. The mean GOHAl score was statistically improved p-value $<0.001$. Table-IV

For male patients, before treatment mean GOHAI score was $21.61 \pm 2.59$ and after treatment mean GOHAI score was improved and was 26.31 \pm 2.14 . The mean GOHAl score was statistically improved in male patient, $p$-value $<0.001$. For female, before treatment mean GOHAl score was 19.34 \pm 2.70 and after treatment mean GOHAl score was improved and was $26.44 \pm 2.49$. The mean GOHAl score was statistically improved in female patients, $p$-value $<0.001$. Table-V

\begin{tabular}{|l|c|}
\hline & Age (Years) \\
\hline Mean & 71.78 \\
\hline Std. Deviation & 7.60 \\
\hline Range & 24.00 \\
\hline Minimum & 60.00 \\
\hline Maximum & 84.00 \\
\hline
\end{tabular}

Table-I. Descriptive statistics of age (Years)

\begin{tabular}{|l|c|c|}
\hline & Frequency & Percent \\
\hline $60-70$ & 24 & 43.6 \\
\hline $71-80$ & 20 & 36.4 \\
\hline$>80$ & 11 & 20.0 \\
\hline Total & 55 & 100.0 \\
\hline
\end{tabular}

Table-II. Frequency distribution of age groups

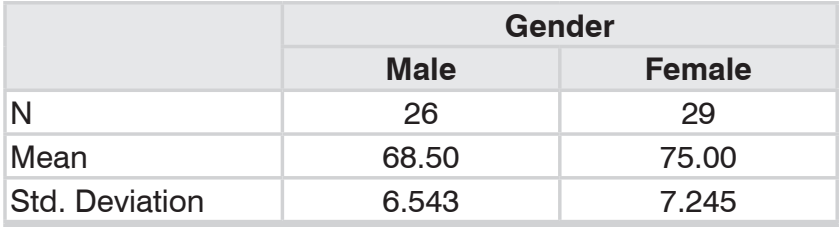

Table-III. Comparison of age in relation to gender

\begin{tabular}{|l|c|c|}
\hline & Pre Score & Post Score \\
\hline Mean & 20.46 & 26.32 \\
\hline Std. Deviation & 2.86 & 2.34 \\
\hline Range & 13.00 & 7.00 \\
\hline Minimum & 15.00 & 22.00 \\
\hline Maximum & 28.00 & 29.00 \\
\hline p-value & \multicolumn{2}{|c|}{$<0.001$} \\
\hline
\end{tabular}

Table-IV. Comparison of gohai score pre and after treatment

\begin{tabular}{|l|l|c|c|c|}
\hline \multicolumn{2}{|c|}{} & Mean & $\begin{array}{c}\text { Std. } \\
\text { Deviation }\end{array}$ & P-Value \\
\hline \begin{tabular}{l|l|c|} 
Gohai Score \\
(Male)
\end{tabular} & Pre Score & 21.61 & 2.59 & \\
\cline { 2 - 4 } & Post Score & 26.31 & 2.14 & \multirow{2}{*}{$<0.001$} \\
\hline $\begin{array}{l}\text { Gohai Score } \\
\text { (Female) }\end{array}$ & Pre Score & 19.34 & 2.70 & \\
\cline { 2 - 4 } & Post Score & 26.44 & 2.49 & \\
\end{tabular}

Table-V. Comparison of gohai score pre and after treatment in male patients

\section{DISCUSSION}

Prosthodontist poses great challenges in successful treating edentulous patients. Rehabilitation for edentulous patients has been described as a combination of function, comfort, esthetics phonetics. It is not beyond the dentist's ability to provide comfort and function in an increasing percentage of the edentulous patients. Ratio in treating edentulous patients successfully has increased due to developments in new materials and techniques. Successful denture esthetics would compensate for lost alveolar bone, properly positioned anterior teeth for lip support, and re-establishing the correct vertical dimension of occlusion with proper tooth selection are important aspects of denture esthetics. Esthetically satisfactory prostheses add in increased psychological success factors. ${ }^{16,17,18}$

In complete denture insertion satisfaction of patients is one of the difficult aspects. A good denture appearance is basically subjective 
appreciation of tooth length, width, shape, shade and their correlation with gingiva, lips, commissars and also facial features. ${ }^{19}$ In the present study, 55 edentulous subjects; 29 male and 26 female patients were selected. Complete denture fabricated under slandered conditions. In current study GOHAl score was 21.61 and after treatment mean GOHAl score was improved and was 26.31 after complete denture insertion are same as Shigli K. ${ }^{20,21,22,23}$

Silva MES ${ }^{4}$ investigated that after insertion of the complete removable prostheses improved the quality of life. These results are consistent with the present study.

Inuki $\mathrm{M}^{10}$, Butt $\mathrm{A}^{19}$, Allen $\mathrm{PF}^{25}$, Peterson $\mathrm{PE}^{24}$ and Ellis $\mathrm{JS}^{21}$ they found that there is a difference in score of GOHAI which is much lower than current study.

Moriya $S^{9}$ reported that positive correlation was found between same score of GOHAl as that of present study. In contrast to present study Forgie $\mathrm{AH}^{22}$ and Ellis $\mathrm{JS}^{21}$ found that there is much lower score of GOHAI than present study.

Following the current study a guideline was proposed for edentulous patients to after providing complete denture; they improve quality of life by improving functional and esthetic.

\section{CONCLUSION}

From the results of current study the following conclusion were drawn:

1. Patients reported improvement in function and esthetic after provision of complete dentures.

2. It is concluded that the most patients after getting prosthetic treatment were satisfied and it is an important predictor in the assessment of quality of life.

3. The quality of life among complete denture wearers in the both arches was better as compared to the quality of life among nondenture wearers.

4. Prosthetic replacement by complete denture helps the individuals to maintain better oral health.
Copyright@ 19 Apr, 2019.

\section{REFERENCES}

1. AL-Omiri MK; karasneh J. Relationship between oral health related quality of life, satisfaction, and personality in patients with prosthodontic rehabilitations. Journal of Prosthodontics. 2010; 19:29.

2. Inoue M, John M, Tsukasaki H, Furuyama C, Baba K. Denture quality has a minimal effect on healthrelated quality of life in patients with removable dentures. J Oral Rehabil. 2011; 38:818-26.

3. Al-AISheikh HM; Comparison of patient satisfaction and dentist evaluation of removable partial dentures therapy among Saudi female patients. J Pak Dent Assoc. 2011; 4:239-43.

4. Silva MES; Magalhaes CS; Ferreira EF; Complete removable prostheses: From expectation to (dis) satisfaction. Gerodontology. 2009; 26:143-9.

5. Stober T; Danner D; Lehmann F; Seche A-C; Rammelsberg $\mathrm{P}$; Hassel AJ; Association between patient satisfaction with complete dentures and oral health-related quality of life: two year longitudinal assessment. Clin Oral Invest. 2012; 16:313-8.

6. Viola AP, Takamiya AS, Monteiro DR, Barbosa DB; Oral health-related quality of life and satisfaction before and after treatment with complete dentures in a Dental School in Brazil. J Prosthodont Res. 2012; $57: 36-41$

7. Shigli K; Hebbal M; Assessment of changes in oral health related quality of life among patients with complete dentures before and one month post insertion using Geriatric Oral Health Assessment Index. Gerodontology. 2010; 27:167-73.

8. Dable RA1, Nazirkar GS, Singh SB, Wasnik PB. Assessment of Oral Health Related Quality of Life Among Completely Edentulous Patients in Western India by Using GOHAl. J Clin Diagn Res. 2013; 7(9):2063-7.

9. Abud MC, Figueiredo MD, dos Santos MB, Consani RL, Marchini L. Correlation of prosthetic status with the GOHAl and TMD indices. Eur J Prosthodont Restor Dent. 2011; 19(1):38-42.

10. Inuki M, Baba K, John MT, Igarashi Y. Does Removable Partial Denture Quality Affect Individual's Oral Health. Dent Res 2008; 87:736-9. 
11. Idrees N, Ghani F. Demands, Needs, Expectation, Pattern and reasons among patients for treatment with fixed dental prostheses. Postgrad Med Inst 2008; 22:313-9.

12. Hassel JA, Rolko C, Grossman CAC, Ohlmann B, Rammelsberg P. Correlations between self ratings of denture function and Oral Health -Related Quality of Life in different age groups. Int J Prosthodont 2007; 20:242-4.

13. Leung $\mathrm{KCM}$, Pow EHN. Oral rehabilitation with removable partial dentures in advanced tooth loss situations. Hong Kong Dental Journal 2009; 6:39-45.

14. Rezaei $\mathrm{M}^{1}$, Rashedi V, Khedmati Morasae E. A Persian version of geriatric oral health assessment Index. Gerodontology. 201415 in press.

15. John MT, Hujoel PP, Miglioretti DL, Leresche L, Koepsell TD, Michaelis W. Dimensions of oral health related quality of life. J Dent Res 2004; 83:956-60.

16. Mehl C, Kern M, Freitag-Wolf S, Stat D, Wolfart M, Brunzel S, Wolfart S. Does the oral health impact profile questionaire measure dental appearance? Int J Prosthodont 2009; 22:87-93.

17. Bekes K, John MT, Schaller HG, Hirsch C. OHRQoL in patient seeking care for dentine sensitivity. $J$ of Oral Rehabil. 2009; 36:45-51.

18. Wong ATY, Mcmillian AS, McGrath C. Oral Health Related Quality of Life and severe hypodontia. J Oral Rehabil 2006; 33:869-83.
19. Butt $A$. Oral health related quality of Life in complete denture patients [Dissertation] Karachi. Coll Physicians Surg Pak 2007.

20. Gift HC, Aitchison KA. Oral health, health and health related quality of life. Med Care 1995; 33:5 -77.

21. Walter $\mathrm{MH}$, Woronul Jl, Tan $\mathrm{KH}$, Lenz $\mathrm{U}$, Koch $\mathrm{R}$, Boening WK, Pinchbeck JY. Oral health related quality of life and its association with sociodemographic and clinical findings in $\mathbf{3}$ northern outreach clinics. JCDA 2007; 73:153-153e.

22. Allen PF. Assessment of oral health related quality of life. Health Quality of Life Outcomes 2003; 1:40-8.

23. Pallegedara C, Ekanayake L. Effect of tooth loss and denture status on oral health-related quality of life of older individuals from Srilanka. Community Dent Health 2008; 25:196-200.

24. Peterson PE. The world oral health report 2003. Continuous improvement of oral health in the $21^{\text {st }}$ century. The approach of the WHO Global oral health programme. Comm Dent Oral Epidemiol 2003; 56:86372.

25. Allen PF, McMillan AS. A longitudinal study of quality of life outcomes in older adults requesting implant prosthesis and complete removable dentures. Clinical Oral Implant Research 2003; 14:173-9.

\begin{tabular}{|c|l|l|l|}
\hline \multicolumn{3}{|c|}{ AUTHORSHIP AND CONTRIBUTION DECLARATION } \\
\hline Sr. \# & \multicolumn{1}{|c|}{ Author(s) Full Name } & Contribution to the paper & Author(s) Signature \\
\hline 1 & Gotam Das & Manuscript writing. \\
\hline 2 & Khezran Qamar & Manuscript writing. \\
\hline 4 & M. Haseeb Rana & Data collection. \\
\hline 5 & Zaheer Hussain Chachar & Proof reading. \\
\hline 6 & Kinza Mushtaque & Literature review. \\
\hline
\end{tabular}

